\title{
FROM DISTANCE EDUCATION TO FRAGILE CONTEXTS: A STUDENT VOICE RESEARCH IN THE THIRD SPACE
}

\author{
Luisa Zecca, Valeria Cotza \\ University of Milano-Bicocca (ITALY)
}

\begin{abstract}
The lockdown forced us to switch from a face-to-face to a distance education, prompting us to re-think the learning and teaching processes. The "digital inequality" [11] exacerbated the disadvantages of the students who were already vulnerable, as students with disabilities or difficulties also due to educational poverties. Moreover, this emergency highlighted some critical issues that have long been afflicting the learning support at school, as the precariousness of educational networks. For this reason, we designed an explorative qualitative project [18] involving both students and teachers and educators, based on the theoretical framework of Social Justice Education according to Cochran-Smith [19-20], who suggests a theory of justice for Teacher Education connecting the distributive justice with the political struggles against disparities and inequities. Support teachers and educators involved, who work from Primary to Secondary School in a wide area around Milan and Monza-Brianza, are also students who are attending at the University of Milano-Bicocca; so, we availed ourselves of a Student Voice approach [23] with a twofold significance, aimed at both school-going students and working students, which guaranteed the right to express themselves and participate in re-designing learning and teaching processes.
\end{abstract}

Interviews were conducted and video-recorded on digital platforms, with consents, following two nondirective and semi-structured interview protocols, validated by the research team. 13 working students were interviewed by researchers, to explore their representations about some key concepts (as fragility and inclusion) and their reflections on distance teaching and their professional role. Working students in turn interviewed their pupils (10 in all, with Italian or non-Italian citizenship, with learning disabilities, behavioral and emotional disorders, language problems or family discomfort), to collect their memories before the lockdown and their opinions and emotions about distance learning. These interviews were conceived as in-depth relationships [28] capable of triggering a process of self-reflection especially in working students, who thus experienced research as training path and internship practice. It configured itself as a Service-Learning Research [24] with methodological contaminations between research and training [25-26], which refers to the frame of field experiences in Teacher Education as proposed by Zeichner [30] through the so-called "Third Space Theory", which explores the spaces in-between two or more educational contexts or experiences (both offline and online). Educational third spaces are hybrid spaces that configure themselves as zones of continual negotiation and transformation, with a reciprocal approach between "knowledge creator" and "knowledge receiver" [31].

Preliminary results show a re-designing of learning environment, bringing out categories such as issues related to a bad Wi-Fi connection, the self-consciousness of own learning processes, the ease of access to lessons, a re-thinking of autonomy and the role of playing in learning. The school emerges as a place of life: according to the practitioners' testimonies, the distance denied the role of the body and authentic relationships. In particular, this first analysis of data highlights a fragility not only of people, but also of educational contexts, projecting us towards an ecological perspective.

Keywords: Qualitative research, distance learning, fragility, Student Voice, Teacher Education.

\section{INTRODUCTION}

According to a recent survey by Save the Children [1], in Italy the lockdown prompted by the COVID-19 emergency exacerbated phenomena such as early school leaving (explicit and implicit) and educational poverties. These phenomena were already widespread before the pandemic, given that under current public policy only about 4\% of GDP is invested in education and universities (latest data available: 2018). As reported by Eurostat [2], for years now the percentage of Early Leavers from Education and Training (ELET) in Italy has been around $14 \%$, which is well above the European average. Equally alarming are the drop-out rates recorded during compulsory schooling [3]. Unfortunately, these statistics are destined to worsen because of the pandemic. Indeed, the school closure during the lockdown caused an increase in the so-called "learning loss", i.e. the failure to learn cognitive - but also physical and socio-emotional - skills, because pupils became isolated. The emergency had especially devastating effects on children 
from socially and culturally disadvantaged contexts [4-5], giving rise to that "educational disconnection" which during the lockdown was reflected in the phenomenon of "missing pupils", who all too often became "invisible pupils".

While, on the one hand, the educational disconnection heightened the difficulties of students who were already in state of vulnerability or disability (to the point that some of them became totally "invisible"), on the other hand, it revealed previously latent educational fragilities, corresponding to new dimensions of educational poverty. In general, the fragility is a characteristic feature of our contemporary era, that is not confined to specific persons or particular social groups, but rather affects the existential dimension of humanity as a whole, calling into question doubt, uncertainty, precariousness [6]; more specifically, "educational fragility" encompasses disadvantages, distress and difficulties (such as disadvantages in the socio-cultural, familial, economic and linguistic spheres; psychological, emotional, communication, relational and behavioral problems; learning difficulties and cognitive disorders), both certified and noncertified, that require specific treatments or care actions in order to prevent openly deviant behaviors or situations of serious inequality [7]. The isolation brought on by the emergency exacerbated all these vulnerabilities, worsening the existing educational inequalities and eliciting the need for a more extensive educational support, that includes care and accompanying. The pandemic scenario has also led to the clear recognition of a new dimension of social inequality: the so-called "digital inequality".

Although ours is a society steeped in digital culture, the technology as a means to overcome social differences appears to be a real myth, which is continuously being debunked by violation of the right to Internet access due to the so-called "digital divide" [8]. Closing down schools reinstated the gap between those who have access to computers and network connections and those who lack these resources and thus are excluded from the benefits of digital society. For example, in Italy a national research conducted by SIRD on distance learning during the public health emergency found that only $74 \%$ of students were fully reached [9]. The emergency has forced us to re-think the processes of teaching and learning, also bringing to light another aspect of particular importance: it is not enough to equip students with PCs, tablets and broadband for the digital divide to end or narrow. Thus, beyond the relatively narrow issue of "access to technology", we find what Hargittai terms the "second level digital divide" [10] or "digital inequality" [11]: this divide consists of differences in individuals' ability to make use of digital media, which in turn are directly proportional to their level of socio-cultural capital. Many studies have shown that digital inequality is influenced by multiple factors, such as the socio-economic and cultural status of one's family, the level of education, disabilities or special educational needs, the ethnic background and the gender [12-14]; this is especially so in the current age of "second modernity", with its pervasive digital technologies and new post-industrial mode of production, which is typical of "informational capitalism" (as defined by Castells [15]). Opportunities for using digital media - which in turn give access to education and training, world of work, information services and broader civil society - depend more and more directly on individual resources, giving rise to phenomena such as social uprootedness, loneliness in pursuing self-realization and communicative individualization [16]. Therefore, an already precarious social equilibrium, when put to the test by the abrupt digital expansion that pervaded all our vital interstices, was suddenly disrupted, worsening conditions of vulnerability and fragility to the point that some people were denied fundamental rights, beginning with the right to education. In schools and education more generally, the emergency triggered educational poverties that had previously latent or dormant, forcing researchers and teachers to address critical issues that have long been challenging the activities and services called to provide learning and socio-educational support in schools to fragile students, who are disproportionately affected by inequalities. The educators who do their work in schools have the task of facilitating inclusion and preventing marginalization, through a process of psycho-social interaction aimed at supporting both individuals and groups at risk of social exclusion, so that they can develop their resources in a changing community.

\section{THEORETICAL FRAMEWORK AND METHODOLOGY}

In light of the above backdrop, the present study was informed by a set of "sensitizing concepts", i.e. "background ideas that inform the overall research problem», starting points for the research design that drive the data analysis, by offering "ways of seeing, organizing, and understanding experience» [17]. Starting from these sensitizing concepts, we formulated two preliminary research questions, which we later progressively revisited as the project proceeded.

1 What impact did the distance learning - and more generally, embracing a more holistic vision, the distance education as a whole - have on the most fragile students, whether or not they were receiving educational or learning support? 
2 How is "educational fragility" perceived by teachers and educators, and how did this concept change during the school closure?

In April 2020, in the COVID-19 pandemic scenario, we began to think about conducting a qualitativeexploratory research project on the perceptions and representations of vulnerable students, support teachers and educators working at school, concerning the educational issues posed by remote relationships; this was with a view to better defining these problems and the variables implicated in them [18]. In light of the fact that the prolonged school closures were severely affecting the most vulnerable students and the most fragile educational systems, thereby increasing inequalities, we situated our research within the theoretical framework of Social Justice Education. More specifically, we followed the approach of Cochran-Smith [19], who has proposed a theory of Teacher Education for social justice and equity. A key component of this model is forming critical practitioners to promote agency and engage in advocacy [20]. According to Cochran-Smith, a theory of social justice should rise to the challenge of connecting the concept of "distributive justice", which is attributed key importance in modern liberal democracies, with the political struggles against inequalities and oppression of certain marginalized social groups, who have been deprived of their rights, identity and recognition [21]; hence, a teacher trained in Social Justice Education should be able to recognize differences in the distribution of educational resources and opportunities and strive to ensure that - even for the most disadvantaged students (who often belong to ethnic minorities or marginalized social groups) - the school functions as a "social elevator". Such teachers are thus reflective researchers [22], who through their professional action reflect and lead others to reflect on the school system as an ideological apparatus of power; they increase students' awareness of their own social condition and of the dynamics underpinning democratic societies. Accordingly, our own study needed to facilitate the full exercise of freedom of speech and the right of self-expression, as well as the active contribution of our participants to the resulting processes of change and teaching and learning. Therefore, we decided to adopt an approach from the Englishlanguage literature, which is still little used in Italy, inspired by the "Student Voice" movement [23], which sees in the "voice" of its students a transformative force capable of triggering innovative processes. Thus, we began to give shape to a research project under the theoretical hat of Social Justice Education; the challenge that we set out to meet was that of combining the urgency to listen to the "live voice" of students and the exploration of the perceptions and representations - both cognitive and emotional - of teachers and educators. This would enable us to examine a number of key problems that had "exploded" during the school closure. In addition, in light of our theoretical framework of reference, we began to think that such a study could have the potential to be considered within the research strand of Teacher Education, as it could offer a training opportunity to teachers and other education practitioners.

An opportunity to further develop our research design presented itself at the beginning of the course "Design and Evaluation of Educational Services and Interventions with Laboratory", delivered in elearning mode by the University of Milano-Bicocca precisely in March-May 2020, right in the middle of the pandemic lockdown period; in fact, during one of the first lessons, while discussing the final group essay assignment, a number of working students (enrolled on the Master's Degree Course in Education and employed as educators and both classroom and support teachers) raised the need to give voice to their own students, who were too often forgotten or deprived of the full right to speak. We therefore decided to include the figure of the working student in our research design and adopt a perspective of Teacher Education; in this way, our Student Voice approach took on a twofold value, because it was not only going to be applied to younger students attending compulsory schooling, but also teachers and educators who are still completing their training and therefore themselves students. 13 working students enrolled on the e-module ( 2 classroom teachers, 3 support teachers and 8 educators), working across a large geographical area comprising the provinces of Milan, Como, Lecco, Monza-Brianza, Novara and Varese, from Primary to Secondary School level, joined the project. Hence, our research design partially transfigured the traditional Student Voice approach by pursuing the teacher preparation aspect of Social Justice Education, especially with regard to processes of reflexivity and self-reflexivity in relation to educational practices.

The 13 working university students were thus coopted onto the research team (which also included a member of Faculty and a PhD student) and invited to reflect not only on their professional practice, but also on the tools required to conduct a project committed to furthering social justice goals. Hence, ours was designed to be a Service-Learning Research [24] that combined methodological contaminations from field research and professional development in education, especially in terms of narrative, reflexive and dialogical components [25-26]. Given the physical isolation imposed by the lockdown, all the research team's meetings took place online, via Google Meet. The team first reflected on the coconstruction of data and meanings, deciding to adopt the methodological framework of constructivist Grounded Theory [27] and the in-depth interview [28] as its leading qualitative tool for exploring the 
manifold, multi-faceted and above all "socially acute" educational issue before it. Hence, we began to work collaboratively on the development of two non-directed and semi-structured interview protocols, the first to be addressed to school-going students with learning or educational difficulties and the second to the working students themselves. This research design enabled us to look beyond the traditional binary distinction between practical and academic knowledge and enter a space, the so-called "third space", characterized by continual processes of hybridization, namely a dimension (whether physical or virtual, as in our study) that encourages a more egalitarian dialectical relationship among participants beyond the bounds of conventional hierarchical social structures [29]. As experienced by Zeichner [30], creating third spaces in the field of Teacher Education means opening real intermediate spaces of negotiation and transformation located between two or more contexts of experience. This helps to break down the boundaries that all too often prevent practitioners from reflecting and working effectively, with unity of purpose, to enhance the significant learning of their most fragile students. Among the multiple interpretations of Third Space Theory that have been put forward over time, we here appeal to those that see the third space as a bridge between different types of knowledges and experiences - which, as such, has the power to introduce us into participatory paradigms - and a conversational space of critical research and radical resistance, with the power to modify perspectives and generate a mutual relationship between those who "produce" knowledge and those who "receive" it [31]. Thus, within the framework of our study, our initial spontaneous inclination to generate third (virtual) spaces of exchange and discussion led us even greater awareness of the intrinsic potential for use (in both theory and practice) of this extraordinary educational dispositive, which really generates democracy.

The 23 interviews were conducted and video-recorded, with the participants' consent, in the same third spaces provided for discussion and reflection among peers: i.e. on digital platforms (mainly Meet). Later the recordings were faithfully transcribed, and non-verbal communication (such as prolonged silences, wandering eye movements, facial expressions that were particularly meaningful in context, laughter including nervous laughter, anxiety, agitation etc.) was observed with a view to accessing interviewees' moods and some of the implicit meanings underlying their words. The working students involved in the project, 13 in all (see Tab. 1), were interviewed by the other members of the research team in the period between 6 and 20 June, 2020 (average interview duration: 1h 15'), following a jointly validated interview protocol divided into five sections. The structure was as follows: 1. professional experience, in terms of length of work experience, the age of children or youths worked with and the reasons why these students need support, the type of support provided and the interviewee's professional development pathway; 2 . interviewee's representations of fragility and inclusion, in order to reflect about his/her own practice in relation to the concepts of "educational fragility" and "inclusion" and the meanings associated with a hypothetical project to combat educational fragility (with its main characteristics and potential risks from the interviewee's perspective); 3 . professional role and educational learning methodology, in terms of how the interviewee defines and describes his/her own professional role and methodology (also with respect to colleagues and other practitioners), then probing his/her thoughts about the networking (with schools, families and possibly socio-educational and healthcare services); 4. interviewee's perception about how the students he/she serves perceive his/her person and educational support; 5 . interviewee's experience of distance education during the COVID-19 public health emergency, with the elicitation of three words describing the positive aspects of this experience and three words describing the negative aspects, also directing the interviewee's thoughts to the immediate future and the re-opening of schools and services: what aspects would the interviewee like to recover and what aspects would he/she like to change? The non-directive and semi-structured protocol meant that interviewees were relatively free to express themselves and organize their discourse as they wished, engendering a chain of narrative mise en abyme, which we sought to reinforce by constantly inviting the interviewees to shape their answers around examples drawn from their professional experience. The interviewer's stance was that of a nonjudgmental listener, who intervened concisely and only when necessary, often using a mirroring technique to verify the correct interpretation of the interviewee's replies or elicit further elaboration of a given point [28]. 
Table 1. Professional and geographical profiles of the interviewed teachers and educators.

\begin{tabular}{l|l|l|l}
\hline \hline \multicolumn{1}{c|}{ Interview code } & Interviewee's name & \multicolumn{1}{|c}{ Professional role } & Location of work \\
\hline 1-ECD & Alessandro Sa. & day center educator & Borgomanero (NO) \\
\hline 2-ESPS1 & Alice Se. & school educator & Monza \\
\hline 3-ESS2 & Serena C. & school educator & Castellanza (VA) \\
\hline 4-CC & Erica O. & cooperative coordinator & Meda (MB) \\
\hline 5-ESP & Carlotta F. & school educator & Buccinasco (MI) \\
\hline 6-ESPS1ACS2 & Nicoletta B. & $\begin{array}{l}\text { school educator and } \\
\text { communication assistant }\end{array}$ & Calolziocorte (LC) \\
\hline 7-ICP & Greta C. & classroom teacher & Varedo (MB) \\
\hline 9-ESS1 & Laura P. & support teacher & greater Milan area \\
\hline 10-ISP & Edoardo B. & school educator & Milan \\
\hline 11-ISP & Mariangela C. & support teacher & Milan \\
\hline 12-ECD & Martina C. & support teacher & Basiano-Masate (MI) \\
\hline 13-ICISS1 & Riccardo R. & day center educator & Como \\
\hline \hline
\end{tabular}

The final section of the interview, focused on the interviewee's recent experience of distance education, was devised to bridge the gap between the cognitive and emotional universe of educational staff and that of the most vulnerable students, who were also explicitly asked about their experience during the suspension of in-presence schooling due to the pandemic. The children and young people to be involved in the project were identified by the working students themselves within their respective work contexts, among the pupils they were currently working with. Thus, the working students combined their (selfreflexive) professional development exercise - which draws on a Student Voice approach - with the opportunity to take on the habitus of a researcher. They interviewed their own students (whom they had selected following sustainable criteria for defining "fragile students" based on our theoretical framework of reference): this allowed a relaxed climate of mutual trust to be established. So, between May 25 and July 23, 2020 (average interview duration: 20'), 10 interviews were conducted with Primary and lower Secondary School students, aged between 7 and 13 years (five of whom had been officially diagnosed with disorders of various kinds and degrees of severity), and who presented: autism spectrum, specific learning disorders, generalized development disorders, language issues (including due to an immigrant background), conduct disorders, socialization difficulties, oppositional-provocative behaviors, attention deficit and hyperactivity, emotional disorders, family issues or social disadvantage. Again, the interview protocol was jointly validated by the research team and was divided into three parts: 1 . questions aimed at eliciting the students' memories of school before the lockdown and reconstructing facts, events and significant situations (Do you remember your last day at school? What do you remember?), focusing also on their emotional perceptions and the meaning that the school has for them (What do you miss about school? What do you not miss? Can you give me some examples?); 2. an invitation to reflect on their recent experiences of distance education, with a view to drawing out its specific features, but also the different offerings that had been made available to them and the role played by their teachers (Can you tell me three good things and three bad things about distance learning? Can you give me some examples?); 3. questions designed to elicit more general judgements about this unusual period in their lives, including in terms of its existential implications, also asking the interviewees to imagine the near future and put forward their "own proposals" about how the life at school and the school itself could be improved (What will you miss about this period? What won't you miss? What do you think going back to school will be like? What would you like to find in September?). In this last section, which was particularly challenging especially for students with cognitive and emotional difficulties, more accessible alternative questions were formulated, to be used if an interviewee was struggling to answer the questions in the standard protocol (What did you like about this quarantine period? What did you discover - three good things? What bad things did you discover? What would you like to find different at school? What would you like to change after COVID-19?). At the end of each session, the interviewee was invited to add anything else he/she would like to have said but had not been asked: some children and young people took advantage of this space to disclose more personal details or share their conjectures or proposals, 
thus leveraging the in-depth interview as a tool for reflection and self-representation. For some students, being interviewed by an adult and even video-recorded put them to the test as they attempted to cope with shyness, performance anxiety, linguistic or cognitive difficulties.

Analysis of the interviews is still ongoing. As planned, we have begun by examining the data from the interviews conducted with the working students. We will next study and process the data from the interviews with children and youths. In keeping with our theoretical framework, we are exploring the data following a constructivist Grounded Theory methodology [27], using ATLAS.ti software to categorize.

\section{RESULTS}

Actively listening to and developing an in-depth understanding of the experiences of teachers and their most fragile students, thus fulfilling their right to speak - including during emergencies - and enabling them to play a key role in our society (as also recommended in non-educational studies, focused on the psycho-physical well-being of children in times of COVID-19 [32]), can make a decisive contribution to the stakeholder reflection and the formulation of active policies, both during the post-pandemic period and, more generally, in the ordinary management of public affairs [33]. The emergency did nothing other than draw attention to problematic educational issues that, in light of their social urgency, would have deserved a considered and responsible response well before the COVID-19 lockdown.

\subsection{From the limits inherent in fragility to its educational potentialities}

The first key category that emerges from the data analysis is fragility (educational and non), understood as a resource and a potentiality. This is in contrast with the most common interpretation of fragility as a weakness and a limitation. Educational fragility was represented by the interviewees as:

1 a latent potentiality, waiting to be seen, heard and understood;

2 a transformative strength to address the fragilities and explore how to offer appropriate support to the people we care for;

3 a resource for generating reflections about the relationship between teacher and student;

4 an opportunity to reflect on the fragility of teachers and educators and, by extension, of contexts.

Therefore, the fragility offers us the possibility to change our pedagogical outlook, not only by viewing all fragile situations as "learned situations" [34], but also by looking beyond the meaning most commonly attributed to fragility: that of a weakness, problem, or deficit. (It is no coincidence that one interviewee, A.Sa., commented, in relation to educational fragility: «Then, there is always the negative meaning in our work. In other words, there is always the concern that you have to work with people who have problems, who have deficits, who are missing something» [1-ECD]). A.Se.'s words exemplify the alternative view of educational fragility as a secret potentiality outlined above, "something that is waiting», a «bubble ready to burst», which requires a certain kind of listening and the opposite of an arrogant attitude on the part of the practitioner. Working on a student's fragility is thus an action to be undertaken jointly, in the context of a mutual exchange between educator and student:

[...] so, everything can be fragility on the one hand, but if we put the term "educational" together with fragility, it can be transformed into a potentiality. So, for me, educational fragility is a hidden potentiality or a listening, a... a bubble ready to burst as you listen, I mean, if I imagine fragility... I mean, I would never want to approach fragility in a presumptuous way... like, "you are fragile and you need my help». No! For me, this... this distinction between roles is useful, but at a strategic level; at the human level, it is a mistake for me not to make. So, for me, educational fragility is really something that is waiting to be seen, looked at, understood together and confronted together. [...] so, it is a mutually enabling process, in my opinion. (2-ESPS1)

Thus, we can observe a stance that seeks to transfigure the negative implications of fragility, leveraging it to activate a process of self-reflection on the educator's own experience, with a view to identifying how best to address educational fragility. As in the words of another interviewee, S.C., who conceptualized fragility as something to be used:

Fragilities are not necessarily negative, I mean... I don't view the term "fragility" as having a negative meaning, because probably these things also help us to deal with... situations, to question ourselves a little and the experiences we are having, to try to understand how 
we can possibly use these fragilities or what to use to provide support for these fragilities. (3-ESS2)

As reflected in the words of the interviewees, the meaning that the world of school generally attributes to fragility is stubbornly persistent: it is taken to be a synonymic counterbalance of difficulty, flaw, or limit. Recognizing the category of so-called "fragile students" certainly has the merit of increasing the number of students entitled to receive special attention and instruments, including not only those who have been diagnosed with particular disorders but also those who have not and who, as such, are often even more exposed to the risk of the educational failure [35]. In fact, another respondent, N.B., stated that:

\begin{abstract}
[Educational fragility] means having difficulty relating to others, it can mean having difficulty understanding the instructions that are given and therefore needing mediation to understand what is required, it means needing alternative tools, which are usually not... are not immediately considered by the teacher. (6-ESPS1ACS2)
\end{abstract}

However, once we accept that fragility cannot be reduced to a mere special educational need, it emerges that the idea of fragility as a potentiality is in itself a resource: teachers and educators who adopt this pedagogical outlook are more inclined to draw connections between the fragilities of their students and the fragility within its existential dimension (where the human being is understood as «something that can be broken at any moment» [12-ECD], as another interviewee, R.R., maintained). Accordingly, the fragilities of the students are mirrored in the fragilities of their teachers and educators and vice versa. Hence, the fragility of the student speaks to the fragility of the practitioner, whose self-understanding triggers a process of empathy and transformation of limits into strengths, as M.C. pointed out:

\begin{abstract}
[...] educators as human beings are partly fragile and, especially when I was working at a residential care center, I learned that the main thing for educators is to understand their own fragile points and ideally to transform them into strengths, because they can help you to better understand the difficulties of the person in front of you, because he/she might have the same difficulties as you; so from the point of view of empathy, fragility is seen as a positive and we put it out there. Educational fragility could also be in a negative sense the difficulty of putting yourself out there; for me, that is also a fragility. (11-ISP)
\end{abstract}

«It's as though people have so many little cracks and you can stand there looking inside, peeking at what's inside» (M.C.). This metaphor is emblematic of the gaze of the educator, who cannot overlook, as reflected in the comments of many interviewees, the key notion of "context".

\title{
3.2 Towards an ecology of educational fragility
}

Hence, a category that is key to the interpretation of our results is the fragility of educational contexts themselves, which crucially can exacerbate or even generate the educational fragilities of children and young people. By "educational context" we mean a microsystem, namely a frame of activities, roles and interpersonal relationships of which the developing individual has experience, that possesses particular physical and concrete characteristics and includes other people with certain features of personality, temperament and belief systems [36]. The interviewees specify that the fragile educational contexts are those that do not cater for the needs of their students (to the point of producing new fragilities); therefore, a fragile educational context requires:

1 to be known in depth, before quality educational and learning interventions can be implemented;

2 to be approached, to work on it, from an ecological perspective [37].

The recent switch to distance education in the context of the emergency has raised awareness of the extent to which the characteristics of the educational setting influence learning. As also observed in an ongoing qualitative study led by Mortari [38], during the lockdown the school setting that was functional to attaining good learning disappeared and schools were presented with decisions "from on high" that frequently failed to consider the needs of different local contexts. The challenges of distance learning have reminded us that educational experiences and practices are closely interrelated with historically situated contextual features, that constrain the individual's subjective possibilities [34]; the context, in its both micro and macro dimensions, is so crucial that, apparently paradoxically, some of the students' educational fragilities go unnoticed in contexts other than the school setting. As interviewee A.Se. observed, in relation to the meaning of educational fragility:

Educational fragility emerges as a function of context... So, for example, if I am walking down the street, nobody would think of saying: "That person has an educational fragility». No! So, in my opinion, the word "educational" emerges precisely when someone enters a 
context that has certain ... that has its own particular structure and so brings to light a certain type of problem, that perhaps another context would not bring out. (2-ESPS1)

Therefore, the concept of "fragility" should not be absolutized, but always related to context. From this perspective, the educational fragilities of some children and young people may occur as the obvious consequence of contexts that are unable to adequately respond to their needs as students, setting off dangerous dynamics of demotivation and distrust. This was the case of the virtual educational context that all teachers suddenly found themselves working in: some students, who before these particular circumstances arose had never shown any evident signs of fragility, now regressed or underwent a crisis [39]. As E.O. pointed out:

Because, therefore, a lot of the time, in my opinion, the fragilities that we see are not really the child's... but the setting's, which cannot respond to the child at that point in time, and so perhaps, by modifying something where we can, we may be able to draw out his competence a bit more. (4-CC)

These words point up the fact that context is something that can be modified, on which we can act to obtain improvements in students. The same interviewee, E.O., also argued that the context «will always behave in the same way, if we only work on the child. And therefore we need to have a better vision of the whole», while another interviewee (C.F.) commented, in relation to addressing fragility: "One can work on one's awareness of one's own potential, and not only of one's own potential per se, but also in relation to the context. What can I do in this context?» (5-ESP). The interviewees agree that familiarity with the context «in all its variability» (C.F.) is a prerequisite for conducting quality educational and learning work; some of them, embracing a more systemic vision, proposed attending not only to the child but also to the educational environment, working on the context and its components. We next cite two of the most emblematic commentaries that pointed to a concept of structural fragility, that is to say the fragility of educational contexts themselves:

We need to work on the context we have in front of us [...] in this period, what has been the fragility? The fact that so many children could not get access as they were supposed to. Whether because they didn't have a computer, or because they are foreign [...]. And so, if we want to work on that, we need to modify the medium by which we go about reaching them. (E.O., 4-CC)

[...] educational fragility in the relationship: I am also thinking about the failings in a certain sense that educational networks very often have, and that yes, constitute a fragility; because we speak about educational networks, because basically a network must support the child and then maybe some connection is severed and makes the whole network fragile and everything falls apart. [...] and educational fragility perhaps also lies in... on the part of the teacher, not being able to recognize the child's precise needs, that is to say also... more than fragility it is a lack of resources, of tools on the part of the teacher. (M.C., 11ISP)

Thus, a preliminary interpretation of the results prompts us to theorize an ecological perspective of the educational fragility, in the light of which other categories of analysis could also be better defined. In any case, not only the teachers but also the children and young students interviewed invoked the concept of "context": on the one hand, they emphasized the extent to which the distance learning context - which prevented a relationship of authentic care from being established - had negatively influenced the quality of their classes (for example, Wi-Fi connections that "came and went", making it difficult for the students to follow and inducing them to move away from their computers); on the other hand, a certain ease of access to lessons and materials, including the opportunity to record and save videos on smartphone devices, appeared to have facilitated meaningful learning. The students' words act to re-define and redesign their previous learning environments at multiple levels, assigning an increasingly important role to the smartphone, which might even be viewed as a real prosthesis thanks to which carrying out playful educational activities (quizzes, interactive materials, or virtual competitions with classmates), that are perceived as contributing to school well-being. Moreover, the online lessons, the opportunity to freely manage their time and the challenges associated with emergency distance learning seem to have affected the students, both in terms of their autonomy and awareness of their learning processes: in fact, some of the students were able to accurately identify the conditions, dynamics and strategies that were most conducive to their own learning. In many cases, these conducive conditions were associated with physically attending school rather than with distance education. Indeed, most of the students had missed their classmates, break times, gym, or lunch breaks. Therefore, they re-confirmed the status of 
school as a place of life and sociality, which can and should certainly be improved upon (the students themselves made some proposals in this regard), but nevertheless remains irreplaceable.

\section{CONCLUSIONS}

Our initial interpretation of the results analysed to date suggests that the awareness of the outcomes of emergency distance education in a pandemic scenario opens up a new perspective of inquiry, prompting the formulation of an ecological theory of educational fragility that would include the fragility of contexts and not only that of people, in keeping with the ICF (International Classification of Functioning, Disability and Health). The design of such a theoretical and analytical perspective could contribute to defining new in-depth knowledge-construction tools (including also for fragile contexts) in support of the practice of teachers, educators and practitioners more generally, in order to derive more refined conceptualizations and examinations for re-thinking not only the individual interventions, but also the relationships between these and the educational work as a whole.

\section{REFERENCES}

[1] Save the Children, La scuola che verrà, September 4, 2020. Retrieved from https://s3.savethechildren.it/public/files/uploads/pubblicazioni/la-scuola-che-verra.pdf

[2] EUROSTAT, Early Leavers from Education and Training, 2020. Retrieved from https://ec.europa.eu/eurostat/statistics-explained/pdfscache/1150.pdf

[3] MIUR, Una politica nazionale di contrasto del fallimento formativo e della povertà educativa. Cabina di regia per la lotta alla dispersione scolastica e alla povertà educativa, January, 2018. Retrieved from https://www.miur.gov.it/documents/20182/0/Rapporto+sul+contrasto+del+ fallimento+formativo.pdf/7575f155-63f9-479a-a77f-1da743492e92?version=1.0\&t= 1515601957911

[4] UNESCO, Adverse Consequences of School Closures, April 21, 2020. Retrieved from https://en.unesco.org/covid19/educationresponse/consequences

[5] E. M. Onyema, N. C. Eucheria, F. A. Obafemi, S. Sen, F. G. Atonye, A. Sharma and A. O. Alsayed, "Impact of Coronavirus Pandemic on Education", Journal of Education and Practice, vol. 11, no. 13, pp. 108-121, 2020.

[6] A. Canevaro, Nascere fragili. Processi educativi e pratiche di cura. Bologna: EDB, 2015.

[7] C. Girelli and A. Bevilacqua, Leggere le fragilità educative a scuola per intervenire. Una ricerca per sostenere i processi di crescita degli studenti nelle scuole trentine. Trento: IPRASE, 2018.

[8] J. Van Dijk, The Deepening Divide: Inequality in the Information Society. Thousand Oaks: SAGE Publications, 2005.

[9] SIRD National Research, Per un confronto sulle modalità di didattica a distanza adottate nelle scuole italiane nel periodo di emergenza COVID-19, 2020. Retrieved from https://www.sird.it/wpcontent/uploads/2020/07/Una_prima_panoramica_dei_dati.pdf

[10] E. Hargittai, "Second Level Digital Divide: Differences in People's Online Skills", First Monday, vol. 7, no. 4, 2002. Retrieved from https://firstmonday.org/ojs/index.php/fm/article/view/942/864

[11] E. Hargittai and Y. P. Hsieh, "Digital Inequality", in The Oxford Handbook of Internet Studies (W. H. Dutton, ed.), pp. 129-150, Oxford: Oxford University Press, 2013.

[12] F. J. B. Pagá, J. L. Martínez and M. C. C. Máiquez, "Internet Use by Secondary School Students: A Digital Divide in Sustainable Societies?", Sustainability, vol. 10, no. 3703, 2018. Retrieved from https://www.mdpi.com/2071-1050/10/10/3703/htm

[13] B. Wessels, "The Reproduction and Reconfiguration of Inequality. Differentiation and Class, Status and Power in the Dynamics of Digital Divides", in The Digital Divide. The Internet and Social Inequality in International Perspective (M. Ragnedda and G. W. Muschert, eds.), pp. 17-28, London: Routledge, 2013.

[14] R. J. Krumsvik, "From Digital Divides to Digital Inequality. The Emerging Digital Inequality in the Norwegian Unitarian School", US-China Education Review, vol. 5, no. 9, pp. 1-17, 2008. 
[15] M. Castells, The Information Age: Economy, Society and Culture. Vol. I. The Rise of the Network Society. Oxford: Blackwell, 1996.

[16] M. Gui, "Disuguaglianze in rete. II divario di competenze e strategie d'uso di Internet nella teoria sociale e in due studi empirici su giovani italiani", Polis, vol. 21, no. 2, pp. 245-273, 2007.

[17] K. Charmaz, "Grounded Theory: Objectivist and Constructivist Methods", in Strategies for Qualitative Inquiry (N. K. Denzin and Y. S. Lincoln, eds.), pp. 249-291, Thousand Oaks: SAGE Publications, 2nd ed., 2003.

[18] L. Lumbelli, "Qualità e quantità nella ricerca empirica in pedagogia", in Manuale critico della sperimentazione e della ricerca educativa (E. Becchi and B. Vertecchi, eds.), pp. 101-133, Milano: Franco Angeli, 1984.

[19] M. Cochran-Smith (ed.), Walking the Road: Race, Diversity, and Social Justice in Teacher Education. New York: Teachers College Press, 2004.

[20] M. Cochran-Smith, "Teacher Education for Justice and Equity: 40 Years of Advocacy", Action in Teacher Education, vol. 42, no. 1, pp. 49-59, 2020.

[21] M. Cochran-Smith, L. Ludlow, F. Ell, M. O'Leary and S. Enterline, "Learning to Teach for Social Justice as a Cross Cultural Concept: Findings from Three Countries", European Journal of Educational Research, vol. 1, no. 2, pp. 171-198, 2012.

[22] D. A. Schön, II professionista riflessivo. Per una nuova epistemologia della pratica professionale. Bari: Dedalo, 1993.

[23] V. Grion and A. Cook-Sather (eds.), Student Voice: prospettive internazionali e pratiche emergenti in Italia. Milano: Guerini, 2013.

[24] J. Eyler and D. E. Giles Jr., Where's the Learning in Service-Learning? San Francisco: JosseyBass, 1999.

[25] G. Asquini (ed.), La ricerca-formazione. Temi, esperienze e prospettive. Milano: Franco Angeli, 2018.

[26] C. Bove, Ricerca educativa e formazione. Contaminazioni metodologiche. Milano: Franco Angeli, 2015.

[27] K. Charmaz, Constructing Grounded Theory. London: SAGE Publications, 2nd ed., 2014.

[28] S. Tusini, La ricerca come relazione. L'intervista nelle scienze sociali. Milano: Franco Angeli, 2006.

[29] H. Bhabha, "The Third Space", in Identity, Community, Culture and Difference (J. Rutherford, ed.), pp. 207-221, London: Lawrence and Wishart, 1990.

[30] K. Zeichner, "Rethinking the Connections Between Campus Courses and Field Experiences in College- and University-Based Teacher Education", Journal of Teacher Education, vol. 61, no. 12, pp. 89-99, 2010.

[31] H. L. Hallman, "Community-Based Field Experiences in Teacher Education: Possibilities for a Pedagogical Third Space", Teaching Education, vol. 23, no. 3, pp. 241-263, 2012.

[32] S. Raman, M. Harries, R. Nathawad, R. Kyeremateng, R. Seth and B. Lonne, "Where Do We Go from Here? A Child Rights-Based Response to COVID-19", BMJ Paediatrics Open, vol. 4, no. 1, 2020. Retrieved from https://www.ncbi.nlm.nih.gov/pmc/articles/PMC7299026/

[33] D. DeMatthews, D. Knight, P. Reyes, A. Benedict and R. Callahan, "From the Field: Education Research During a Pandemic", Educational Research, vol. 49, no. 6, pp. 398-402, 2020.

[34] C. Palmieri, "L'educatore nei servizi: marginalità, svantaggio, disabilità", Annali online della Didattica e della Formazione Docente, vol. 8, no. 11, pp. 85-97, 2016.

[35] C. Girelli and A. Bevilacqua, "La prevenzione del fallimento educativo e della dispersione scolastica nei documenti internazionali e nazionali", RicercAzione, vol. 10, no. 2, pp. 17-29, 2018.

[36] U. Bronfenbrenner (ed.), Making Human Beings Human: Bioecological Perspectives on Human Development. Thousand Oaks: SAGE Publications, 2005.

[37] U. Bronfenbrenner, Ecologia dello sviluppo umano. Bologna: II Mulino, 1986. 
[38] L. Mortari (promoter), La didattica al tempo del Covid-19: i vissuti degli insegnanti. Research study in progress.

[39] D. Fantozzi, "Interdisciplinarità e bisogni educativi speciali in tempi di lockdown sanitario obbligatorio: una connessione reale anche in ambiente virtuale", Italian Journal of Special Education for Inclusion, vol. 8, no. 1, pp. 138-148, 2020. 